\title{
Crescimento, produtividade e qualidade de raízes de rabanete cultivadas sob diferentes fontes e doses de adubos orgânicos
}

\author{
Caciana C Costa $^{1}$; Cristina D de Oliveira1; César José da Silva ${ }^{1}$; Paulo César Timossi ${ }^{1}$; Izabel Cristina Leite ${ }^{2}$ \\ ${ }^{2}$ UNESP/FCAV, Dep ${ }^{\text {to }}$ Biologia Aplicada, Via de acesso Prof. Paulo Donato Castellane, s/n, 14884-900 Jaboticabal-SP; E-mail: \\ ccc_agro@hotmail.com; 'Pós-graduandos em Produção Vegetal.
}

\section{RESUMO}

Avaliou-se o efeito da aplicação de doses de húmus de minhoca e de esterco bovino no crescimento de rabanete (Raphanus sativus L.), cultivar Crimson Giant, de agosto a setembro de 2002. Fez-se semeadura direta do rabanete com desbaste nove dias após, para adequar ao espaçamento de $0,20 \times 0,08 \mathrm{~m}$. Utilizou-se delineamen-

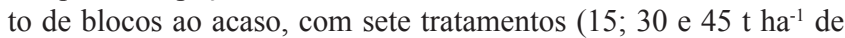
húmus de minhoca e esterco bovino curtido, além do controle sem adição de fertilizante), em três repetições. Houve maior acúmulo de massa seca nas folhas em relação aos demais órgãos da planta, com acúmulo contínuo até os 13 dias após a semeadura, com posterior redução, quando ocorreu o desenvolvimento da raiz. As doses e fontes de adubos orgânicos aplicados pouco influenciaram no crescimento e nas produtividades total e comercial de raízes. O húmus de minhoca apresentou a menor porcentagem de raízes rachadas e isoporizadas nas doses de 9,2 e 20,4 tha- ${ }^{-1}$, respectivamente. A dose de esterco bovino, de 21,3 $\mathrm{t} \mathrm{ha}^{-1}$ promoveu a maior porcentagem de raízes rachadas e a de $45 \mathrm{t} \mathrm{ha}^{-1}$ proporcionou redução em relação à de $15 \mathrm{tha}^{-1}$.

Palavras-chave: Raphanus sativus L., adubação orgânica, desenvolvimento, produção, distúrbios fisiológicos.

\begin{abstract}
Growth, productivity and quality of radish roots cultivated under different sources and doses of organic fertilizers

This experiment was carried out in Jaboticabal, São Paulo State, Brazil, between August and September 2002, to evaluate the effect of different vermicompost doses and cattle manure on growth, yield and quality of radish roots (Raphanus sativus L.), cultivar Crimson Giant. Direct sowing of the radish was followed by thinning nine days after, adjusting the spacing to $0.20 \times 0.08 \mathrm{~m}$. A randomized blocks experimental design was used, with seven treatments $(15 ; 30$ and $45 \mathrm{t} \mathrm{ha}^{-1}$ of earthworm humus or cattle manure, and a control without fertilizer addition), in three replications. There was higher dry mass accumulation in the leaves than in other organs, with continuous accumulation until 13 days after sowing, with further reduction, when the root development occurred. Doses and sources of organic fertilization slightly influenced growth, total productivity and quality of commercial roots. Earthworm humus reduced the percentage of cracked and spongeous roots in the doses of 9.2 and $20.4 \mathrm{tha}^{-1}$, respectively. Doses of $21.3 \mathrm{tha}^{-1}$ of cattle manure promoted the highest percentage of cracked roots, while the dose of $45 \mathrm{t} \mathrm{ha}^{-1}$ reduced this percentage, when compared to the use of $15 \mathrm{tha}^{-1}$.
\end{abstract}

Keywords: Raphanus sativus L., organic fertilization, growth, production, physiologic disturbances.

\section{(Recebido para publicação em 19 de setembro de 2005; aceito em 3 de fevereiro de 2006)}

$\mathrm{O}$ rabanete é uma cultura de ciclo curto e o ambiente exerce grande interferência na qualidade de suas raízes. Segundo Leite (1976) variações nas condições de temperatura e umidade do solo durante o desenvolvimento das plantas podem prejudicar a produtividade e a qualidade das raízes. A umidade do solo deve ser mantida elevada, próxima a $100 \%$, ao longo de todo o ciclo da cultura (Pereira et al., 1999).

De acordo com Cecílio Filho et al. (1998) outro fator que pode prejudicar a produtividade comercial de rabanete é a ocorrência de desordens fisiológicas de origem nutricional. Respostas positivas têm sido observadas com a aplicação de adubos orgânicos. Santos et al. (2002), testando o uso de composto de lixo no desenvolvimento do rabanete, nas doses de 30; 60; 90 e 120 tha $^{-1}$, observaram que doses crescentes do composto proporcionaram aumento nos níveis de nutrientes disponíveis, teores de matéria orgânica e valores de $\mathrm{pH}$ do solo, além de incrementarem a produção de massa seca, tanto da parte aérea como do sistema radicular do rabanete.

Segundo Magalhães (1979) na avaliação das diferenças no comportamento de cultivares influenciadas por determinadas práticas agronômicas, efeitos de competição, climáticos e/ou fatores intrínsecos associados com a fisiologia da planta, a análise de crescimento é um método de grande valia.

Vários índices fisiológicos devem ser utilizados na tentativa de explicar e compreender as diferenças de comportamento de uma cultivar submetida a diferentes tratamentos e citam que entre os mais utilizados, encontram-se os índices de área foliar e de colheita, taxas de crescimento da cultura, de crescimento relativo e de assimilação líquida (Pereira \& Machado, 1987).

O objetivo deste trabalho foi avaliar o crescimento das plantas e, a produção e qualidade das raízes de rabanete cultivadas sob diferentes doses de húmus de minhoca e de esterco bovino curtido.

\section{MATERIAL E MÉTODOS}

Conduziu-se o experimento na Faculdade de Ciências Agrárias e Veterinárias da UNESP em Jaboticabal (SP), cujas coordenadas são $21^{\circ} 15^{\prime} 22^{\prime \prime}$ de latitude Sul e $48^{\circ} 18^{\prime} 58^{\prime \prime}$ de longitude Oeste, estando a uma altitude de $575 \mathrm{~m}$. O clima da região, pela classificação de Köppen, é Cwa predominando o LATOSSOLO VERMELHO 
Eutroférrico típico, textura muito argilosa, A moderado caulinítico oxídico mesoférrico e de relevo suave ondulado a ondulado. As características químicas do solo no local do experimento foram: $\mathrm{pH}\left(\mathrm{CaCl}_{2}\right)=6,4 ;$ M.O. $=35 \mathrm{~g} \mathrm{dm}^{-3}$; $\mathrm{P}($ resina $)=242 \mathrm{mg} \mathrm{dm}^{-3} ; \mathrm{K}=4,20 \mathrm{mmol}_{\mathrm{c}}$ $\mathrm{dm}^{-3} ; \mathrm{Ca}=74 \mathrm{mmol}_{\mathrm{c}} \mathrm{dm}^{-3} ; \mathrm{Mg}=25$ $\mathrm{mmol} \mathrm{dm}{ }^{-3} ; \mathrm{H}+\mathrm{Al}=22 \mathrm{mmol} \mathrm{dm}^{-3} ; \mathrm{SB}=$ $103,2 \mathrm{mmol}_{\mathrm{c}} \mathrm{dm}^{-3} ; \mathrm{T}=123,2 \mathrm{mmol}_{\mathrm{c}} \mathrm{dm}^{-3}$; $\mathrm{V}=82,4 \%$.

O delineamento utilizado foi de blocos ao acaso, com sete tratamentos e três repetições. As parcelas eram de 3,0 x $1,0 \mathrm{~m}$ e apresentavam cinco linhas longitudinais de semeadura, sendo nas avaliações, consideradas úteis as três linhas centrais.

Os tratamentos foram constituídos da aplicação de 15; 30 e $45 \mathrm{t} \mathrm{ha}^{-1}$ de húmus de minhoca e esterco bovino curtido, mais um controle, sem adição de fertilizante. A caracterização química do esterco e do húmus de minhoca foi, respectivamente: M.O.=183,9 e 583,5 g $\mathrm{dm}^{-3} ; \mathrm{C} / \mathrm{N}=9 / 1$ e $13 / 1 ; \mathrm{P}($ resina $)=179$ e $252 \mathrm{mg} \mathrm{dm}^{-3} ; \mathrm{N}=8,82$ e $25,6 \mathrm{~g} \mathrm{~kg}^{-1}$; $\mathrm{K}=2,6$ e 9,4 $\mathrm{mmol}_{\mathrm{c}} \mathrm{dm}^{-3}$. O húmus de minhoca teve como matéria prima o esterco bovino.

Os adubos orgânicos foram incorporados com enxada à camada superficial do solo até $20 \mathrm{~cm}$ com posterior irrigação, visando à uniformização do terreno para a semeadura, que foi realizada com a cultivar Crimson Giant, três dias após. Aos nove dias da semeadura realizou-se o desbaste, adequando-se as plantas ao espaçamento de $0,20 \times 0,08 \mathrm{~m}$.

As plantas foram irrigadas diariamente por aspersão, mantendo a umidade do solo próximo à capacidade de campo. O controle de plantas infestantes foi realizado por capinas manuais. Os dados climatológicos como, temperatura média, precipitação pluviométrica e insolação, foram medidos diariamente.

Durante o crescimento e desenvolvimento das plantas, fez-se a análise de crescimento das mesmas. Para tal, foram realizadas amostragens a cada quatro dias, coletando-se seis plantas por parcela, a partir do nono até o trigésimo dia após a semeadura (DAS).

As plantas coletadas foram lavadas e separadas em limbos foliares, pecíolos, folhas senescentes e raízes, quando presentes. Para cada repetição, por meio do medidor de área (Area Measurement System), mediu-se a área de dez limbos foliares. Em seqüência, todas as partes das plantas foram secas em estufa com circulação de ar, a $80^{\circ} \mathrm{C}$, até peso constante.

De posse dos dados, de massa seca e de área foliar, foram calculados os parâmetros fisiológicos de partição de massa seca, razão de área foliar, área foliar específica, razão de massa de folhas e razão parte aérea/raiz, utilizando-se fórmulas matemáticas propostas por Evans (1972).

$\mathrm{Na}$ amostragem final (30 DAS), além das avaliações de crescimento, foram determinadas as produtividades total e comercial e, a porcentagem de raízes rachadas e isoporizadas. Segundo Filgueira (2003) raízes isoporizadas ocorrem quando os rabanetes tornamse esponjosos e insípidos, reduzindo sua qualidade.

Os dados de produtividade e qualidade das raízes foram submetidos à análise de variância pelo teste $\mathrm{F}$ e as médias de fontes comparadas pelo teste de Tukey, a 5\% de probabilidade (Banzatto \& Kronka, 1995). Os resultados de doses, quando significativos, foram avaliados mediante análise de regressão para cada fonte de matéria orgânica. $\mathrm{O}$ modelo significativo de maior ordem e coeficiente de correlação $\left(\mathrm{R}^{2}\right)$ foi selecionado para expressar o comportamento.

\section{RESULTADOS E DISCUSSÃO}

Na produtividade total e comercial das plantas de rabanete, não houve interação e tampouco efeito significativo para doses e fontes de adubos orgânicos. Possivelmente a não expressão dos efeitos dos adubos orgânicos nas doses incorporadas pode estar relacionada com o teor de matéria orgânica do solo $\left(35 \mathrm{~g} \mathrm{dm}^{-3}\right)$ que, mesmo apresentando-se na classe média, segundo a análise de solo, foi suficiente para o desenvolvimento das plantas de rabanete. Costa (1999), na cultura do alho, também não verificou resultados significativos sobre a produção comercial com aplicações de doses entre 10 e $40 \mathrm{t} \mathrm{ha}^{-1}$ de esterco bovino.
A aplicação de húmus de minhoca e esterco bovino resultou nos valores médios, respectivamente, de 2,38 e 3,25 $\mathrm{t} \mathrm{ha}^{-1}$ para a produtividade total e de 1,12 e 1,57 tha ${ }^{-1}$ de produtividade comercial. Para o controle foram registradas $2,95 \mathrm{t}$ $\mathrm{ha}^{-1}$ de produtividade total e $1,28 \mathrm{tha}^{-1}$ de raízes comerciais. Pantano et al. (2001), para a mesma cultivar, no espaçamento $0,25 \times 0,05 \mathrm{~m}$, obtiveram uma produtividade de $23,52 \mathrm{t} \mathrm{ha}^{-1}$. Torres et al. (2003) na cultivar gigante Wurzburgo, no espaçamento de $0,15 \mathrm{x}$ $0,05 \mathrm{~m}$, registraram uma produtividade de $21,21 \mathrm{tha}^{-1}$.

No presente trabalho, as produtividades obtidas em todos os tratamentos ficaram aquém das encontradas na literatura e podem estar relacionadas com a menor incidência de insolação durante o ciclo da cultura, em conseqüência da ocorrência de elevadas precipitações, chegando a $170 \mathrm{~mm}$ durante a condução do experimento. Segundo Souza et al. (1999) a redução da radiação solar causa decréscimo no tamanho e no peso das raízes.

Para a partição da massa seca (MS) da planta entre limbos, pecíolos e raízes, observaram-se dois comportamentos distintos, ou seja, plantas do tratamento controle, com $45 \mathrm{t} \mathrm{ha}^{-1}$ de húmus (Figura $1 \mathrm{~A}$ ) e 15 e 45 t ha $^{-1}$ de esterco (Figura 1B) apresentaram acúmulo contínuo de massa seca na raiz a partir dos 13 dias após a semeadura (DAS), enquanto que a MS dos limbos aumentou até os 13 DAS e reduziu gradativamente até os 30 DAS.

Nas doses de 15 e $30 \mathrm{t} \mathrm{ha}^{-1}$ de húmus e $30 \mathrm{t} \mathrm{ha}^{-1}$ de esterco a MS das raízes apresentou ganhos dos 13 aos 27 DAS, sendo seguida de um acentuado decréscimo, enquanto a MS dos limbos, que mostrava redução dos 13 aos 27 DAS foi incrementada acentuadamente dos 27 aos 30 DAS. O incremento da massa seca dos limbos para estes tratamentos no final do ciclo da cultura atribuiu-se ao crescimento de folhas pré-existentes e não do surgimento de novas folhas.

Com relação à massa seca dos pecíolos, todos os tratamentos apresentaram comportamento semelhante, ou seja, a massa seca dos pecíolos praticamente não variou, sendo observada apenas pequena redução a 
partir dos 13 DAS, provavelmente devido a translocação para a raiz (Figuras 1A e 1B).

Quanto à razão da área foliar (RAF), a mesma foi muito influenciada pela luz, o que explica a variabilidade dos valores apresentados nas figuras $2 \mathrm{~A}$ e $2 \mathrm{~B}$, independentemente da dose ou fonte de adubo orgânico aplicado e, embora tenham ocorrido picos no aumento da razão da área foliar, houve tendência de redução com o desenvolvimento das plantas, concordando com resultados obtidos por Souza et al. (1999).

Segundo Benincasa (1988), a razão da área foliar declina à medida que a planta cresce, pois, com o crescimento ocorre o aumento da interferência de folhas superiores sobre as folhas inferiores, promovendo auto-sombreamento nas plantas, induzindo o aumento da área foliar sem o correspondente aumento da massa seca da parte aérea.

Uma das componentes da razão da área foliar é a área foliar específica (AFE) e representa o inverso da espessura das folhas. Observou-se que períodos de expansão da lâmina foliar, com conseqüente aumento na área foliar específica, alternaram-se com períodos em que as folhas aumentaram em espessura, com decréscimo na área foliar específica (Figuras 2C e 2D). Isso ocorreu provavelmente devido às condições climáticas, como quedas de temperatura, dias nublado e ocorrência de precipitações, ocasionando poucas horas de brilho solar diário durante as avaliações. Estes resultados concordam com os de Souza et al. (1999) que avaliaram o desenvolvimento de plantas de rabanete submetidas a três intensidades luminosas e observaram aumento da área foliar específica à medida que se diminuiu a intensidade da radiação solar incidente na cultura.

A razão de massa de folhas (RMF) é um componente fisiológico, pois, é a razão entre a massa seca retida nas folhas e a massa seca acumulada na planta toda. Em todos os tratamentos, verificou-se tendência de redução nos valores de razão de massa de folhas à medida que as plantas se desenvolviam, após os 13 dias da semeadura (Figuras 2E e $2 \mathrm{~F}$ ). Ainda nas mesmas figuras, obser-

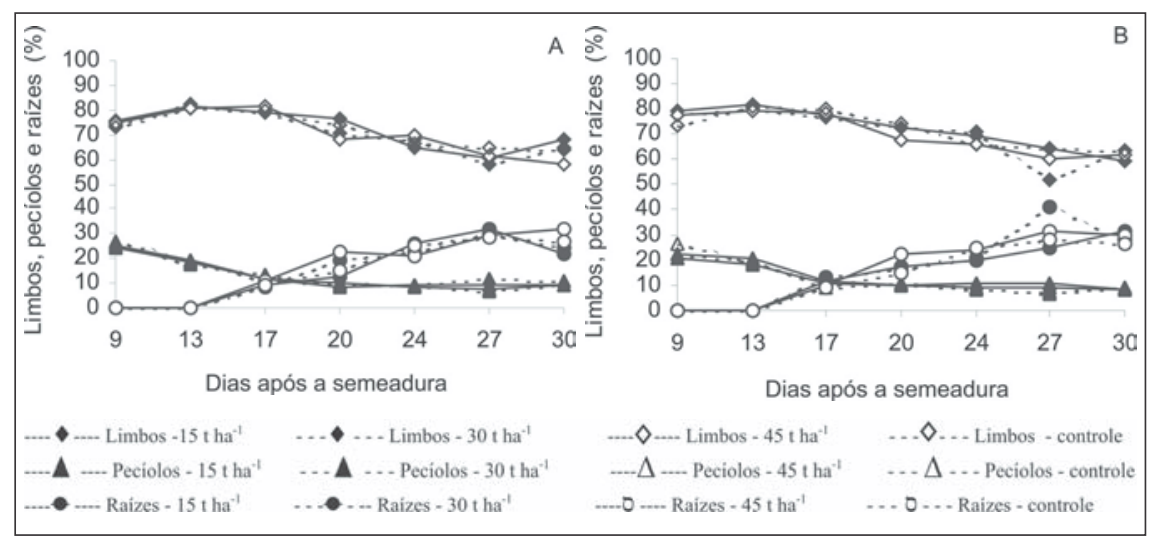

Figura 1. Partição de massa seca de plantas de rabanete submetida a quatro doses de húmus de minhoca (A) e de esterco bovino (B). Jaboticabal, UNESP, 2004.

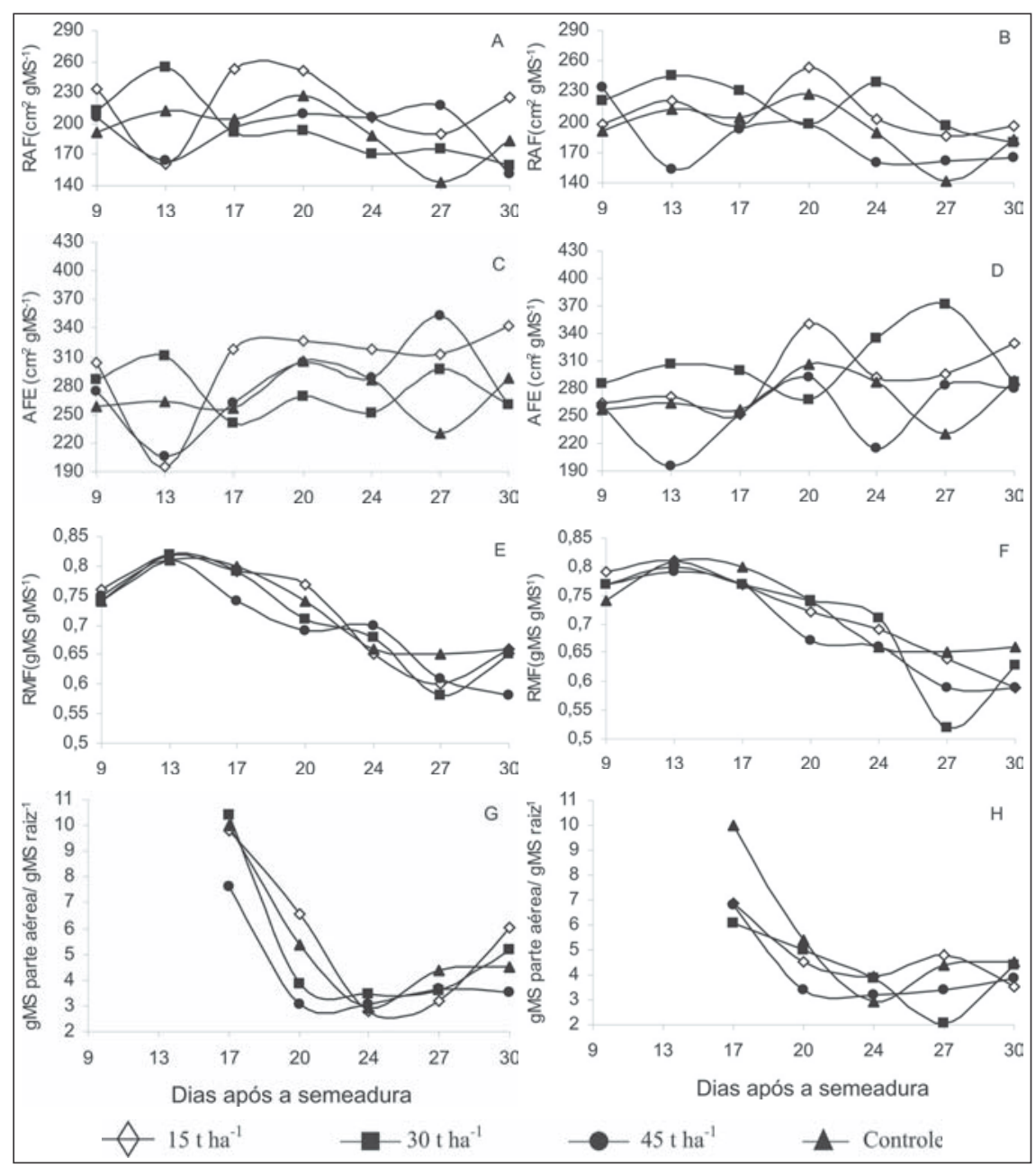

Figura 2. Razão de área foliar (RAF), área foliar específica (AFE), razão de peso de folha (RMF) e razão parte aérea/raiz (RAR) de plantas de rabanete, em função de diferentes doses de húmus de minhoca (A, C, E e G) e esterco bovino (B, D, F e H). Jaboticabal, UNESP, 2004.

va-se que nos tratamentos com 15 e $30 \mathrm{t}$ ha $^{-1}$ de húmus e 30 e $45 \mathrm{t} \mathrm{ha}^{-1}$ de esterco, dos 27 aos 30 DAS ocorreu um aumento na razão de massa de folhas, indicando a retomada do crescimento vegetativo das plantas neste período.
A razão de massa de folhas demonstrou que inicialmente houve o crescimento foliar, levando ao aumento de massa em detrimento do crescimento do restante dos órgãos da planta. No momento em que as folhas atingiram sua 


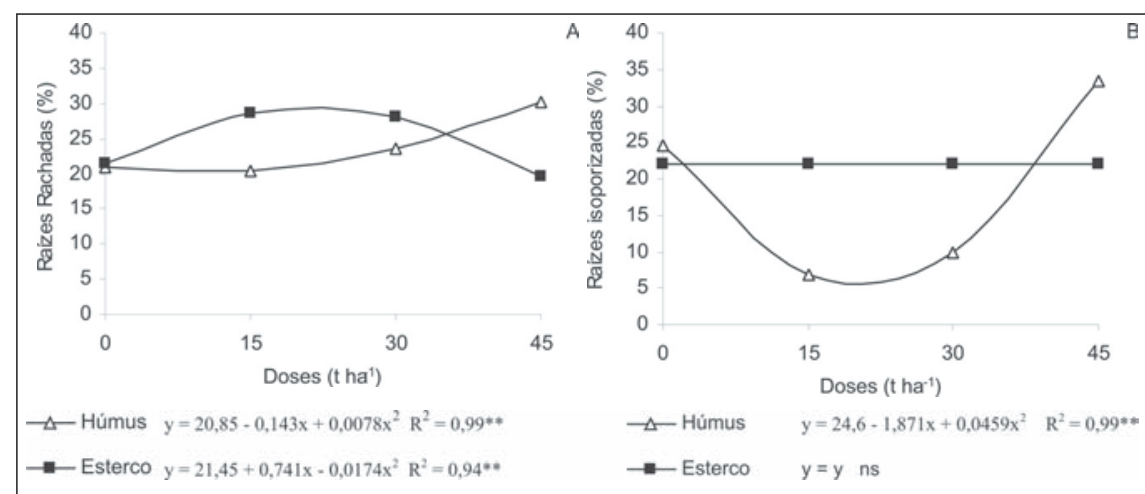

Figura 3. Porcentagens de raízes rachadas e isoporizadas na cultura do rabanete, em função de diferentes doses de húmus de minhoca e esterco bovino. Jaboticabal, UNESP, 2004.

máxima expansão, começou a haver redução da razão de massa de folhas, ou seja, ocorreu direcionamento dos compostos fotossintetizados para a raiz da planta. Como se prolongou a permanência da cultura no campo, a planta retomou o crescimento do aparato fotossintético (folha) provocando aumento na razão de massa de folhas, sendo que estes dados coincidem com os da literatura e obedecem ao comportamento esperado para a cultura (Craker et al., 1983; Souza et al., 1999).

Percebe-se pelas Figuras 2G e 2H, que a razão da MS produzida pela parte aérea e pela raiz não diferiu entre os tratamentos. Verifica-se também que quando as plantas estavam em pleno crescimento vegetativo (17 DAS), a razão parte aérea/raiz foi alta, apresentando nítido declínio no início do crescimento da raiz, em seqüência ocorreu tendência de estabilização no decorrer do ciclo da cultura.

O presente resultado, de razão da massa seca produzida pela parte aérea e pela raiz, contrasta com os obtidos por Cardoso \& Hiraki (2001) que, ao avaliarem doses e épocas de aplicação de nitrogênio, encontraram razão parte aérea/raiz bem inferior em plantas sem adição de nitrogênio. Por outro lado, Pell et al. (1990) observaram maior participação da parte aérea na massa seca total da planta quanto menor foi a dose de nitrogênio aplicada.

Quanto à qualidade das raízes produzidas, o húmus de minhoca apresentou a menor porcentagem de raízes ra- chadas $(19,60 \%)$ e isoporizadas $(5,54 \%)$ nas doses de 9,2 e 20,4 $\mathrm{t} \mathrm{ha}^{-1}$, respectivamente (Figuras $3 \mathrm{~A}$ e $3 \mathrm{~B}$ ).

$\mathrm{O}$ esterco bovino, com relação a porcentagem de raízes rachadas, apresentou respostas de natureza quadrática (Figura 3A). A dose estimada de 21,3 t $\mathrm{ha}^{-1}$ promoveu a maior porcentagem de raízes rachadas $(29,33 \%)$ e a dose de $45 \mathrm{t} \mathrm{ha}^{-1}$ proporcionou redução de $31,76 \%$ de raízes rachadas em relação à de $15 \mathrm{tha}^{-1}$.

Vários fatores podem ter ocasionado a ocorrência de raízes rachadas e isoporizadas. Dentre eles pode ser citada a aplicação dos adubos orgânicos, que possivelmente, liberaram maior quantidade de nitrogênio, pois, conforme Souza (1990), na cultura da cenoura, deformações ocorridas nas raízes podem ser atribuídas à utilização de adubos orgânicos como, por exemplo, o esterco bovino.

A alta incidência de rachaduras nas raízes, verificada no presente trabalho, também pode ser atribuída às oscilações hídrica e térmica no solo, advindas de elevadas temperaturas registradas em alguns dias e à falta de cobertura morta sobre o solo, favorecendo o rápido secamento da camada superficial do solo. Segundo Filgueira (2003) as oscilações hídricas acarretam rachaduras nas raízes de rabanete. Kano \& Fukuoka (1995) citam que durante o período de crescimento de rabanete japonês, temperaturas do solo acima de $30^{\circ} \mathrm{C}$ favorecem a ocorrência de rachaduras externas nas raízes, devido à formação de lignina ao redor das células, induzidas pelo aquecimento. Leite (1976) cita que a aplicação de cobertura morta sobre o solo é uma alternativa relevante para induzir menor variação térmica e hídrica na camada superficial do perfil do solo.

A ausência de resistência, à rachadura e isoporização das raízes, da cultivar Crimson Giant, aliada à colheita realizada aos 30 DAS, contribuíram para a redução da qualidade e conseqüentemente da produtividade comercial das raízes, sugerindo que a colheita, de cultivares de rabanete sem resistência aos distúrbios fisiológicos citados, deve ser feita antes que as raízes atinjam máximo desenvolvimento.

As doses aplicadas de húmus de minhoca e esterco bovino pouco alteraram o desenvolvimento das plantas de rabanete na classe de solo estudada, ocasionando falta de resposta sobre as produtividades total e comercial, e seus efeitos sobre a qualidade são dependentes da interação entre doses e condições climáticas.

\section{LITERATURA CITADA}

BANZATTO DA; KRONKASN. 1995. Experimentação agrícola. 3 ed. Jaboticabal: FUNEP, 247 p. BENINCASA MMP. 1988. Análise de crescimento de plantas: noções básicas. Jaboticabal: FUNEP, $42 \mathrm{p}$.

CARDOSO AII; HIRAKI H. 2001. Avaliação de doses e épocas de aplicação de nitrato de cálcio em cobertura na cultura do rabanete. Horticultura Brasileira, 19: 328-331.

CECÍLIO FILHO AB; FAQUIN V; FURTINI NETO AE; SOUZA RJ. 1998. Deficiência nutricional e seu efeito na produção de rabanete. Cientifica. 26: 231-241.

COSTA CC. 1999. Efeito de diferentes fontes e doses de matéria orgânica na cultura do alho. 44 f. Monografia, Faculdade de Ciências Agrárias, Universidade Federal da Paraíba, Areia.

CRAKER LE; SEIBERT M; CLIFFORD JT. 1983. Growth and development of radish (Raphanus sativus L.) under selected light environments. Annals of Botany, 51: 59-764.

EVANS GC. 1972. The quantitative analysis of plant growth. Londres: Blackweel Scientific Publications, $734 \mathrm{p}$.

FILGUEIRA FAR. 2003. Novo manual de olericultura: agrotecnologia moderna na produção de hortaliças. 2 ed. Viçosa: UFV, 412 p.

KANO Y; FUKUOKA N. 1995. Effects of soil temperature on hollowness in Japanese radish (Raphanus sativus L. cv. 'Gensuke'). Scientia Horticulturae, 61: 157-166.

LEITE IC. 1976. Estudos ecológicos de Raphanus sativus L. cv. Crimson Giant no efeito do comportamento térmico do solo. $122 \mathrm{f}$. Monografia, Faculdade de Ciências Agrárias e Veterinárias, Universidade Estadual Paulista, Jaboticabal. 
MAGALHÃES ACN. 1979. Análise quantitativa de crescimento. In: FERRI MG. (Coord.). $F i$ siologia Vegetal. São Paulo: EPU, EDUSP, p. 331-350.

PANTANO SC; SEABRA JÚNIOR, S; RANGEL MG; HIDALGO AF; CÂMARA FLA 2001. Produção e qualidade de seis cultivares de rabanete em função da idade de colheita Horticultura Brasileira, 19: 2, Suplemento CDROM. Trabalho apresentado no 41 Congresso Brasileiro de Olericultura, 2001.

PELL EJ; WINNER WE; MOONEY HA. 1990.

Response of radish to multiple stresses.I. Physiological and growth response to changes in ozone and nitrogen. New Phytologist, 115 439-446.
PEREIRAAJ; BLANK AF; SOUZA RJ; OLIVEIRA PM; LIMA LA. 1999. Efeitos de níveis de reposição e freqüências de irrigação sobre a produção e qualidade do rabanete. Revista Brasileira de Engenharia Agrícola e Ambiental, 3: 117-120. PEREIRA AR; MACHADO EC. 1987. Análise quantitativa do crescimento da comunidade vegetal. Campinas, Instituto Agronômico de Campinas, 33 p. (Boletim técnico, 114).

SANTOS CMPR; FERREIRA MCL; REIS PAC; BALLESTERO SD; FORTES NETO P. 1999. Efeito de doses crescentes de composto de lixo no desenvolvimento de Raphanus sativus. In: ENCONTRO DE INICIAÇÃO CIENTÍFICA, MOSTRA DE POS-GRADUAÇÃO, 4, Taubaté. Anais eletrônicos...Taubaté: UNITAU, 1999. Disponível em: $<$ http://www.unitau.br/prppq/inicient/vieic/ tabela.resumos.bio.htm>. Acesso em: 18 out. 2002.
SOUZA PA. 1990. Efeito de diferentes fontes de adubos orgânicos sobre a produtividade de cenoura 76 f. Monografia, Faculdade de Ciências Agrárias, Universidade Federal da Paraíba, Areia.

SOUZA JRP; MEHL HO; RODRIGUES JD; PEDRAS JF. 1999. Sombreamento e o desenvolvimento e produção de rabanete. Scientia Agrícola, 56: 987-992.

TORRES CAS; REBOUÇAS TNH; SIQUEIRA LG; SILVA JCG; AMORIM CHF; CARDOSO NS. 2003. Avaliação da densidade de plantio sobre a produção e diâmetro de rabanete. Horticultura Brasileira, 21: 2, Suplemento CDROM. Trabalho apresentado no $43^{\circ}$ Congresso Brasileiro de Olericultura, 2003. 